MATEC Web of Conferences 3, 01076 (2013)

DOI: $10.1051 /$ matecconf/20130301076

(C) Owned by the authors, published by EDP Sciences, 2013

\title{
Modelling the sigma phase
}

R. Mathieu ${ }^{1}$, N. Dupin ${ }^{1}$, J.-C. Crivello ${ }^{2}$, J.-M. Joubert ${ }^{2}$, K. Yaqoob ${ }^{2}$, A. Breidi ${ }^{2}$, J.-M. Fiorani ${ }^{3}$, and N. David ${ }^{3}$

${ }^{1}$ Calcul Thermodynamique, 63670 Orcet, France

${ }^{2}$ CMTR-ICMPE-CNRS Thiais France

${ }^{3}$ Institut Jean Lamour, Vandoeuvre les Nancy, France

The study of the sigma phase is highly relevant for many industrial alloys (steels, superalloys, ...). When this phase forms, the matrix is depleted of strenghtening elements and its needle shape edges constitute sites for fragile rupture. The Calphad approach allows to better design and process alloys to avoid the detrimental effect of such phases. However, the multicomponent descriptions currently available present some weakness in the description of this phase. The present study contributes to a better knowledge of this phase from experimental and DFT basis in order to derive a better multicomponent Calphad description.

The present contribution will compare the 5 sublattice CEF model corresponding to the crystallographic structure using DFT results to different simplifications. 